\title{
Sequence Impedances of Land Single-Core Insulated Cables: Direct Formulae and Multiconductor Cell Analyses Compared with Measurements
}

\author{
Roberto Benato ${ }^{1}{ }^{(\mathbb{D}}$, Sebastian Dambone Sessa ${ }^{1, *(\mathbb{D}}$, Michele Poli ${ }^{2}$ and Francesco Sanniti ${ }^{1}$ (I) \\ 1 Department of Industrial Engineering, University of Padova, 35131 Padova, Italy; \\ roberto.benato@unipd.it (R.B.); francesco.sanniti@phd.unipd.it (F.S.) \\ 2 Terna, 00156 Rome, Italy; michele.poli@terna.it \\ * Correspondence: sebastian.dambonesessa@unipd.it
}

Received: 1 January 2020; Accepted: 25 February 2020; Published: 1 March 2020

check for updates

\begin{abstract}
The paper deals with the sequence impedances (positive/negative and zero sequences) of high- and extra-high-voltage land single-core insulated cables. In particular, it presents the comparisons between sequence impedance measurements and computations. The computations of the sequence impedances are carried out by means of the most important international normative and council references (IEC/Cigré) and of multiconductor cell analysis which is a consolidated and powerful tool developed by University of Padova in order to analyse power frequency regimes of multiconductor asymmetric power systems. The comparisons are presented with reference to four high- and extra-high voltage insulated cables, even if the available ones are much higher: however, the conclusions derived from these four reference cases are general and can be useful for transmission system operators and for power electric system engineers involved in insulated cables. The paper demonstrates, for the first time in technical literature, that direct formulae cannot correctly evaluate the sequence impedances of installed single-core land cable systems. Extensive on-field measurement campaigns have served to this purpose.
\end{abstract}

Keywords: insulated cables; sequence impedances; multiconductor cell analysis (MCA); extra-high voltage; asymmetric systems

\section{Introduction}

In 2012, the first author presented a conference paper with a comparison between analytical formulae of insulated cable sequence impedances and the results of two measurement campaigns [1]. At that time, high-voltage (HV) cables in Italy were short in length, and the experience with such systems was limited. That paper [1] dealt with two HV insulated cables of medium length $(6-8 \mathrm{~km})$. After 8 years, the cable lengths installed in the Italian high and extra-high voltage (EHV) grid have strongly increased: therefore, the amount of experience has also increased thanks to more measurement campaigns. The measurement campaigns have the aim of obtaining on-field sequence impedance values. Once the measurements are available, a comparison with formulae is always performed. Italian Academia, together with Terna, which is the Italian transmission system operator (TSO) and owner, have decided to give electrical engineers a wide account on these comparisons, i.e., sequence impedance measurements compared with analytical and procedural computations. Since it is not possible to present the comparisons for all installed HV and EHV cables, a selection of the more meaningful cases is made in this paper, aiming at covering all the Italian high and extra-high voltage levels $(132-380 \mathrm{kV})$. The importance of the exact knowledge of the sequence impedances of an electric line is paramount both for planning and operating activities: it is worth noting that power flow and 
short circuit studies are always based on them. Furthermore, the correct behaviour of distance relays is strictly dependent upon their correct settings, which are based on the sequence impedances. Also, the assessment of a new insulated cable insertion into the grid needs to know the sequence impedances. Theoretically, the use of zero, positive-negative sequence impedances is only exact if the system is symmetric, since the application of voltage phasors of a sequence causes the circulation only of the same sequence current phasors so that it is possible to compute the ratios between voltage and current phasors (i.e., the impedances). For cable lines, this assumption is only true if the insulated cables are cross-bonded with phase transpositions or if they are cross-bonded in trefoil arrangement [1]. In all other cases, the use of the sequence impedances would be theoretically wrong. However, the error is small for engineering purposes. Even if an insulated cable is cross-bonded with phase transpositions (or in trefoil laying) there could be many causes of asymmetry:

- Different lengths in the minor sections provoke not zeroed induced currents in the screens;

- Joint chambers and terminals which force a flat arrangement with a consequent asymmetry;

- The crossings of interfering services or natural obstacles, if any, usually overcome by directional drillings which may introduce a great cable spacing;

- That the as-built installation is always different from the project.

The presence of these causes has a lower impact for long cables but they would, theoretically, always result in an asymmetric system.

The two most important references for the computation of insulated cable sequence impedances are the IEC 60909-2 [2] and the Cigré Technical Brochure \#531 "Cable Systems Electrical Characteristics" [3]. Other interesting calculation approaches are proposed in [4,5]. Moreover, multiconductor cell analysis (MCA) was presented in the technical literature 10 years ago [6]. It has been applied successfully to the analysis of a great number of asymmetrical/multiconductor systems from overhead lines with one or more ground wires to single-core ac and dc cables with screens and armour, gas insulated lines, and distribution line carriers. Papers [7-13] give some suggestions to deepen such applications, and [14] deals with the validation of the MCA method by exploiting the comparison with experimental measurements. MCA is based on the subdivision of the system into $n$ elementary cells: the model type for the computation of elementary cell impedances can be chosen between Carson theory $[15,16]$, Carson-Clem simplified formulae [17] or Schelkunoff/Wedepohl $[18,19]$ formulae: at power frequency, all the formulations give the same results. With regard to other literature contributions similar to this paper, the authors want to remember the following contributions: [20] is devoted to the measurements of sequence impedances of a $150 \mathrm{kV}$ three-core submarine cable; [21] deals with only one cable systems at $345 \mathrm{kV}$; [22] is a very interesting measurement campaign on a $400 \mathrm{kV}$ cross-bonded cable devoted more to transient behaviour than to power frequency sequence impedances. There are some books [23-25] on cable sequence impedances but none of them expounds comparisons with measurements.

The focus of the paper is to compare the sequence impedance values obtained by applying the IEC/Cigrè and MCA approaches with the experimental measurements performed on real cable installations. The aim of this work is to highlight the accuracy of each estimation method in different installation conditions. In particular, since the IEC/Cigrè formulations do not allow considering the presence of the cable metallic screens in the case of cross-bonding arrangement, the effect of this simplifying hypothesis in the sequence impedance estimation is investigated.

Furthermore, because of the wide carried out measurement campaign performed for different installation scenarios, this paper aims at giving an idea of how the installation area significantly affects the zero sequence impedance of cable lines.

\section{Normative and Council Direct Formulae for Computing Cable Sequence Impedances}

The proposed direct formulae for the computation of sequence impedances $\left(\underline{Z}_{1}-\underline{Z}_{2}\right.$ and $\left.\underline{Z}_{0}\right)$ held in [2] and [3] seem different but it could be demonstrated, by means of simple mathematical passages, that they are exactly the same. IEC 60909-2 [2] gives (1) and (2), i.e., the p.u.l. sequence impedances 
of three single-core cables (in trefoil or flat arrangement but with phase transpositions) without metallic screens:

$$
\begin{aligned}
& \underline{z}_{1}=\underline{z}_{1 \text { Cross-bond. }}=R_{c}+j \omega \frac{\mu_{0}}{2 \pi}\left[\frac{1}{4}+\ln \left(\frac{D_{m}}{r_{c}}\right)\right]\left[\frac{\Omega}{\mathrm{m}}\right] \\
& \underline{z}_{0}=R_{c}+3 \omega \frac{\mu_{0}}{8}+j \omega \frac{\mu_{0}}{2 \pi}\left[\frac{1}{4}+3 \ln \left(\frac{\delta}{\sqrt[3]{r_{c} D_{m}^{2}}}\right)\right]\left[\frac{\Omega}{\mathrm{m}}\right]
\end{aligned}
$$

where $R_{c}$ is the conductor ac p.u.l. resistance (including the skin and proximity effects) $[\Omega / \mathrm{m}] ; \mu_{0}$ is the soil magnetic permeability $=4 \cdot \pi \cdot 10^{-7}[\mathrm{H} / \mathrm{m}] ; D_{m}$ is the geometrical mean distance (GMD) between phases [m], and $r_{C}$ is the phase conductor radius $[\mathrm{m}] ; \delta=1.851 / \sqrt{\frac{\omega \mu_{0}}{\rho_{t}}}$ is the equivalent earth penetration depth (Equation (36) of [26]) in $\mathrm{m}$ (which coincides with Carson distance $D_{\text {Carson }}$ of conductor from the earth return currents usually written as $\left.658 \cdot \sqrt{\rho_{t} / f}[\mathrm{~m}]\right)$, with $\rho_{t}$ soil resistivity in $[\Omega \cdot \mathrm{m}]$ and $\omega=2 \pi f$ angular frequency in $[\mathrm{rad} / \mathrm{s}](f=$ power frequency in $[\mathrm{Hz}])$.

Equation (1) can be used only for three single-core cables where there are no induced currents in the screens: this is the case of positive sequence supply with perfectly cross-bonded screens. As it will be shown in Sections 7 and 8 and has already been highlighted in the Introduction, in real installations, this is never verified (perfect cross-bonding does not exist) so that non-null induced currents flow in the metallic screens. In case of solid-bonded screens, (1) and (2) serve as a basis for (3) and (4):

$$
\begin{gathered}
\underline{z}_{1_{\text {Solid-bonding }}}=\underline{z}_{1}+\frac{\left[\omega \frac{\mu_{0}}{2 \pi} \ln \left(\frac{D_{m}}{r_{s m}}\right)\right]^{2}}{R_{s}+j \omega \frac{\mu_{0}}{2 \pi} \ln \left(\frac{D_{m}}{r_{s m}}\right)}\left[\frac{\Omega}{m}\right] \\
\underline{z}_{0_{\text {Cross-bond. }}}=\underline{z}_{0_{\text {Solid-bond. }}}=\underline{z}_{0}-\frac{\left[3 \frac{\omega \mu_{0}}{8}+j 3 \frac{\omega \mu_{0}}{2 \pi} \ln \left(\frac{D_{\text {Carson }}}{\sqrt[3]{r_{\text {sm }} D_{m}^{2}}}\right)\right]^{2}}{R_{s}+3 \frac{\omega \mu_{0}}{8}+j 3 \frac{\omega \mu_{0}}{2 \pi} \ln \left(\frac{D_{\text {Carson }}}{\sqrt[3]{r_{s m} D_{m}^{2}}}\right)}\left[\frac{\Omega}{m}\right]
\end{gathered}
$$

where $\underline{z}_{1}$ must be computed as in $(1) ; \underline{z}_{0}$ must be computed as $(2) ; r_{s m}$ is the mean screen radius $[\mathrm{m}]=$ $\frac{\left(r_{s i}+r_{s e}\right)}{2}$, with $r_{s i}$ and $r_{s e}$ inner and outer screen radii [m]; $R_{s}$ is the ac screen p.u.l. resistance $[\Omega / \mathrm{m}]$ (for the usual thicknesses of the screens the current can be considered as uniformly distributed so that dc and ac resistances are equal).

With regard to the zero sequence, it is worth remembering that (4) is valid for both solid-bonding and cross-bonding: the cross-bonding screen arrangement has the same effect of the solid-bonding one since the zero sequence currents are in phase such that the screen transpositions do not cancel the induced voltages along a major section.

\section{MCA for Evaluating Sequence Impedances of Cable Systems}

The MCA is based on the principle that the multiconductor system which constitutes a power transmission line can be represented as a cascade of $m$ elementary cells of length $\Delta \ell$. Each cell is modelled by a lumped PI-circuit where the voltage column vectors $\mathbf{u}_{\mathrm{S}}, \mathbf{u}_{\mathrm{R}}$, and the current column vectors $\boldsymbol{i}_{S}, \boldsymbol{i}_{S L}, \boldsymbol{i}_{S T}$, and $\boldsymbol{i}_{R}$ have a number of elements equal to $n$, with $n$ the number of the conductive elements of the system. Figure 1 shows the cell cascade where $S$ and $R$ stand for sending and receiving ends respectively. Being that $\Delta \ell$ is sufficiently small, it is possible to lump the uniformly distributed shunt admittances at both ends of the cell (transverse blocks TS and TR) and to consider separately the longitudinal elements in the block $L$ (where $\boldsymbol{i}_{R L} \equiv \boldsymbol{i}_{S L}$ ) [6-14]. By applying this modelling approach, it is possible to compute the currents and voltages along the cable length for each conductive element of the multiconductor system, i.e., phase conductors, screens, and armour (if present). 


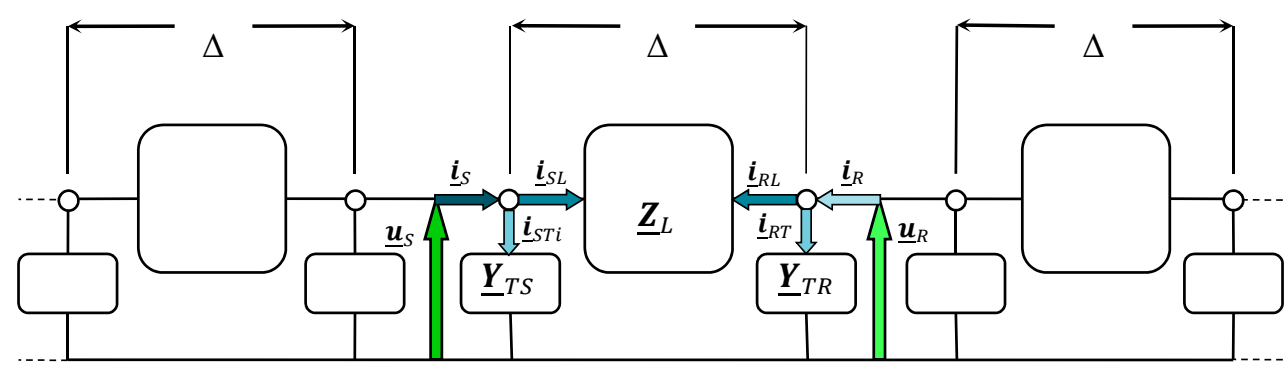

Figure 1. Elementary cell cascade for single-circuit cable line modelling.

With regard to the computations of sequence impedances by means of $M C A$, it is possible to apply three voltage generators, $\underline{u}_{1}, \underline{u}_{2}, \underline{u}_{3}$, of the involved sequence and, once the power frequency regime is solved by knowing the currents $\underline{\underline{i}}_{1}, \underline{i}_{2}, \underline{i}_{3}$ circulating into the phase conductors, to compute the following positive sequence impedances:

$$
\begin{aligned}
& \left.\underline{z}_{1 \_M C A}\right|_{p h 1}=\frac{\underline{u}_{1}}{\underline{i}_{1}} \text { with } \underline{u}_{1}=1 \\
& \left.\underline{z}_{1 \_M C A}\right|_{p h 2}=\frac{\underline{u}_{2}}{\underline{i}_{2}} \text { with } \underline{u}_{2}=\alpha^{2} \\
& \left.\underline{z}_{1 \_M C A}\right|_{p h 3}=\frac{\underline{u}_{3}}{\underline{i}_{3}} \text { with } \underline{u}_{3}=\alpha .
\end{aligned}
$$

If the considered power system is asymmetrical, the three impedances in (5) have different values so that, even with a "theoretical stretch", it is possible to compute a unique sequence impedance meant as an average value, i.e.,

$$
\underline{z}_{1 \_M C A}=\frac{\left(\left.\underline{z}_{1 \_M C A}\right|_{p h 1}+\left.\underline{z}_{1 \_M C A}\right|_{p h 2}+\left.\underline{z}_{1 \_M C A}\right|_{p h 3}\right)}{3} .
$$

Analogously with regard to the zero sequence, this yields

$$
\begin{aligned}
& \left.\underline{z}_{0 \_M C A}\right|_{p h 1}=\frac{\underline{u}_{0}}{\underline{i}_{1}} \text { with } \underline{u}_{0}=1 ; \\
& \left.\underline{z}_{0 \_M C A}\right|_{p h 2}=\frac{\underline{u}_{0}}{\dot{i}_{2}} \text { with } \underline{u}_{0}=1 ; \\
& \left.\underline{z}_{0 \_M C A}\right|_{p h 3}=\frac{u_{0}}{\dot{i}_{3}} \text { with } \underline{u}_{0}=1
\end{aligned}
$$

whose average value is given by

$$
\underline{z}_{0 \_M C A}=\frac{\left(\left.\underline{z}_{0 \_M C A}\right|_{p h 1}+\left.\underline{z}_{0 \_M C A}\right|_{p h 2}+\left.\underline{z}_{0 \_M C A}\right|_{p h 3}\right)}{3} .
$$

\section{Description of the Four Reference Cable Systems}

The first insulated cable line is the so-called "SE Calenzano-SE Rifredi RT" with a total length of $8.325 \mathrm{~km}$ and phase-to-phase nominal voltage of $132 \mathrm{kV}$. Table 1 reports both the laying and single-core cable characteristics. The line is located in a highly urbanised area near Firenze and the soil resistivity is equal to $100 \Omega \mathrm{m}$. The second insulated cable line is the so-called "CP San Giuseppe-CP Portoferraio" with a total length of $5.87 \mathrm{~km}$ and phase-to-phase nominal voltage of $132 \mathrm{kV}$. Table 2 reports both the laying and single-core cable characteristics. The line is located in the Elba Island in a rural and natural area with a soil resistivity of $700 \Omega \mathrm{m}$. The third insulated cable line is the so-called "SE Camin-CP Bassanello" with a total length of $10.851 \mathrm{~km}$ and phase-to-phase nominal voltage of 132 $\mathrm{kV}$. Table 3 reports both the laying and single-core cable characteristics. The line is located in Veneto Region in rural/urban areas with soil resistivity of $100 \Omega \mathrm{m}$. The fourth insulated cable line is the so-called "SE Ferrara Nord-C.le SEF" with a total length of $2.05 \mathrm{~km}$ and phase-to-phase nominal 
voltage of $380 \mathrm{kV}$. Table 4 reports both the laying and single-core cable characteristics. The line is located in the industrialised area of Ferrara with soil resistivity of $100 \Omega \mathrm{m}$. Table 5 reports the dc and ac conductor p.u.l. resistances and other electrical parameters useful in the computations of the four land cable systems.

Table 1. Three single-core insulated cables of $132 \mathrm{kV}$ in SE Calenzano-SE Rifredi RT.

\begin{tabular}{ccc}
\hline Line Geometrical Characteristics & & \\
\hline Total length & $\mathrm{km}$ & 8.325 \\
Trefoil laying length & $\mathrm{km}$ & 6.495 \\
Flat laying (spacing $=1$ m) length & $\mathrm{km}$ & 1.785 \\
Trefoil in ducts length (duct spacing $=0.150 \mathrm{~m})$ & $\mathrm{km}$ & 0.045 \\
Conductor cross section and material & $\mathrm{mm}^{2}$ & $1000 \mathrm{Al}$ \\
\hline Screen Arrangement & $\mathrm{cross}$-bonding \\
\hline Conductor diam. $\left(d_{c}\right)$ & $\mathrm{mm}$ & 38.4 \\
Conductor semic. screen diameter $\left(d_{0}\right)$ & $\mathrm{mm}$ & 42.3 \\
Insulating material diameter $\left(d_{1}\right)$ & $\mathrm{mm}$ & 83.1 \\
Insulating semic. screen diam. & $\mathrm{mm}$ & 85.3 \\
Metallic screen diameter & $\mathrm{mm}$ & 87.5 \\
Screen cross-section & $\mathrm{mm}$ & 85 \\
External jacket diameter & $\mathrm{mm}$ & 96 \\
\hline
\end{tabular}

Table 2. Three single-core insulated cables of $132 \mathrm{kV}$ in CP San Giuseppe-CP Portoferraio.

\begin{tabular}{ccc}
\hline Line Geometrical Characteristics & & \\
\hline Total length & $\mathrm{km}$ & 5.868 \\
Trefoil laying length & $\mathrm{km}$ & 4.743 \\
Open trefoil length (spacing $=0.225 \mathrm{~m})$ & $\mathrm{km}$ & 0.886 \\
Flat laying (spacing $=0.35 \mathrm{~m}$ ) length & $\mathrm{km}$ & 0.239 \\
Conductor cross section and material & $\mathrm{mm}^{2}$ & $1600 \mathrm{Al}$ \\
\hline Screen Arrangement & $\mathrm{cross}$-bonding \\
\hline Conductor diameter $\left(d_{c}\right)$ & $\mathrm{mm}$ & 47.5 \\
Conductor semic. screen diameter $\left(d_{0}\right)$ & $\mathrm{mm}$ & 52.9 \\
Insulating material diameter $\left(d_{1}\right)$ & $\mathrm{mm}$ & 86.9 \\
Insulating semic. screen diam. & $\mathrm{mm}$ & 90.7 \\
Equivalent metallic screen diameter & $\mathrm{mm}$ & 91.93 \\
Copper screen cross-section & $\mathrm{mm}$ & 140 \\
Aluminium screen cross-section & $\mathrm{mm}$ & 60 \\
External jacket diameter & $\mathrm{mm}$ & 106 \\
\hline
\end{tabular}

Table 3. Three single-core insulated cables of $132 \mathrm{kV}$ in SE Camin-CP Bassanello.

\begin{tabular}{ccc}
\hline Line Geometrical Characteristics & & \\
\hline Total length & $\mathrm{km}$ & 10.851 \\
Trefoil laying length & $\mathrm{km}$ & 9.831 \\
Flat laying (spacing $=0.25 \mathrm{~m}$ ) length & $\mathrm{km}$ & 0.204 \\
Trefoil in ducts length (duct spacing $=0.180 \mathrm{~m})$ & $\mathrm{km}$ & 0.267 \\
FlowMole (guide drill system) length (spacing $=0.5 \mathrm{~m})$ & $\mathrm{km}$ & 0.549 \\
Conductor cross section and material & $\mathrm{mm}^{2}$ & $1600 \mathrm{Al}$ \\
\hline
\end{tabular}


Table 3. Cont.

\begin{tabular}{ccc}
\hline Screen Arrangement & \multicolumn{2}{c}{ cross-bonding } \\
\hline Conductor diameter $\left(d_{c}\right)$ & $\mathrm{mm}$ & 49.1 \\
Conductor semic. screen diameter $\left(d_{0}\right)$ & $\mathrm{mm}$ & 51.1 \\
Insulating material diameter $\left(d_{1}\right)$ & $\mathrm{mm}$ & 89.1 \\
Insulating semic. screen diam. & $\mathrm{mm}$ & 93.1 \\
Copper screen inner diameter & $\mathrm{mm}$ & 93.9 \\
Copper screen cross-section & $\mathrm{mm}^{2}$ & 70 \\
Copper screen thickness & $\mathrm{mm}$ & 1.35 \\
Aluminium foil inner diameter & $\mathrm{mm}$ & 97.4 \\
Aluminium foil cross-section & $\mathrm{mm}$ & 61.3 \\
Aluminium foil thickness & $\mathrm{mm}$ & 0.2 \\
External jacket diameter & $\mathrm{mm}$ & 105.8 \\
\hline
\end{tabular}

Table 4. Three single-core insulated cables of $380 \mathrm{kV}$ in SE Ferrara Nord-C.le SEF.

\begin{tabular}{ccc}
\hline Line Geometrical Characteristics & & \\
Total length & $\mathrm{km}$ & 2.05 \\
Trefoil laying length & $\mathrm{km}$ & 1.695 \\
Open trefoil laying length (spacing $=0.20 \mathrm{~m})$ & $\mathrm{km}$ & 0.045 \\
Flat laying (spacing = 0.60 m) length & $\mathrm{km}$ & 0.310 \\
Conductor cross section and material & $\mathrm{mm}^{2}$ & $1600 \mathrm{Cu}$ \\
\hline Screen Arrangement & $\mathrm{cross}-$ bonding \\
\hline Conductor diameter $\left(d_{c}\right)$ & $\mathrm{mm}$ & 49.4 \\
Conductor semic. screen diameter $\left(d_{0}\right)$ & $\mathrm{mm}$ & 53.8 \\
Insulating material diameter $\left(d_{1}\right)$ & $\mathrm{mm}$ & 107.8 \\
Insulating semic. screen diameter & $\mathrm{mm}$ & 110.8 \\
Equivalent metallic screen diameter & $\mathrm{mm}$ & 115.3 \\
Copper screen cross-section & $\mathrm{mm}$ & 122 \\
Lead screen outer diameter & $\mathrm{mm}$ & 121.8 \\
Lead screen cross-section & $\mathrm{mm}$ & 748 \\
External jacket diameter & $\mathrm{mm}$ & 132 \\
\hline
\end{tabular}

Table 5. Electrical characteristics of the four reference cables.

\begin{tabular}{|c|c|c|c|c|}
\hline Electrical Quantity & $\begin{array}{c}\# 1 \\
1000 \mathrm{Al}\end{array}$ & $\begin{array}{c}\# 2 \\
1600 \mathrm{Al}\end{array}$ & $\begin{array}{c}\# 3 \\
1600 \mathrm{Al}\end{array}$ & $\begin{array}{c}\# 4 \\
2500 \mathrm{Cu}\end{array}$ \\
\hline DC p.u.l. conductor resistance at $20^{\circ} \mathrm{C}$ in $\Omega / \mathrm{km}$ & 0.0291 & 0.0186 & 0.0186 & 0.0113 \\
\hline AC p.u.l. conductor resistance at $20^{\circ} \mathrm{C}$ in $\Omega / \mathrm{km}$ & 0.0323 & 0.0227 & 0.0224 & 0.0162 \\
\hline Screen or equiv. screen p.u.l. resistance at $20^{\circ} \mathrm{C}$ in $\Omega / \mathrm{km}$ & 0.216 & 0.0977 & 0.162 & 0.0946 \\
\hline Relative permittivity of insul. & 2.7 & 2.5 & 2.3 & 2.3 \\
\hline
\end{tabular}

\section{Measurement Campaigns}

As soon as a new underground installation is realised, TERNA can decide to perform a measurement campaign before cable operation into the grid. The accuracy class of the used measurement transformers is 0.2 and their characteristics are consistent with $[27,28]$. These campaigns aim at verifying the shunt parameters (chiefly, the phase-to-screen capacitance) and the sequence impedance. The used method is four-wire voltamperometric [29]. In Figure 2, the usual arrangement for the shunt parameter measurements is shown. The phase conductors are open at the receiving end and are energised with the phase-to-ground nominal voltages. The current and voltage magnitudes (by means of current transformers (CTs) and capacitor voltage transformers (CVTs), respectively) and the active power absorbed by the cable together with angles (by means of Ws) allow for the measurement of real and imaginary parts of the shunt admittance. Figure 3 gives the scheme for measuring the positive sequence impedance: the three phases are short-circuited and earthed at the receiving end. In order to perform 
the sequence impedance measurements, three dry-type single-phase delta-wye transformers with rated power of $4 \mathrm{kVA}$ are used. Their transformation ratios are $380 / 25-100 \mathrm{~V} / \mathrm{V}, 50 \mathrm{~Hz}$; the maximum currents for each voltage tap are $25-40,50-80,75-120$, and 100-160 A. The star point (neutral point) is unearthed in order to avoid zero sequence current circulation. The measurements of voltage and current magnitudes and of the angles allow for the computation of positive sequence impedances of the three phases and then their average value. It is worth noting that the scheme also foresees the presence of current probes installed on the metallic screens in order to measure the induced current magnitudes.

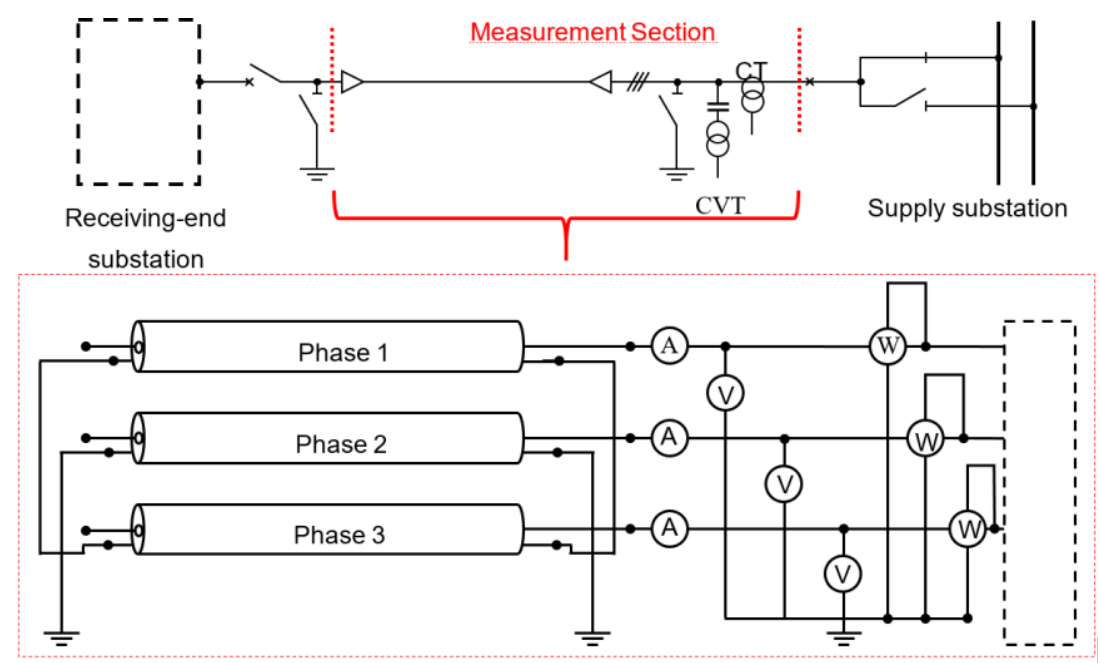

Figure 2. Equipment for measuring the shunt parameters. CT and A-current transformer; CVT and V-capacitor voltage transformer; W-wattmeter.
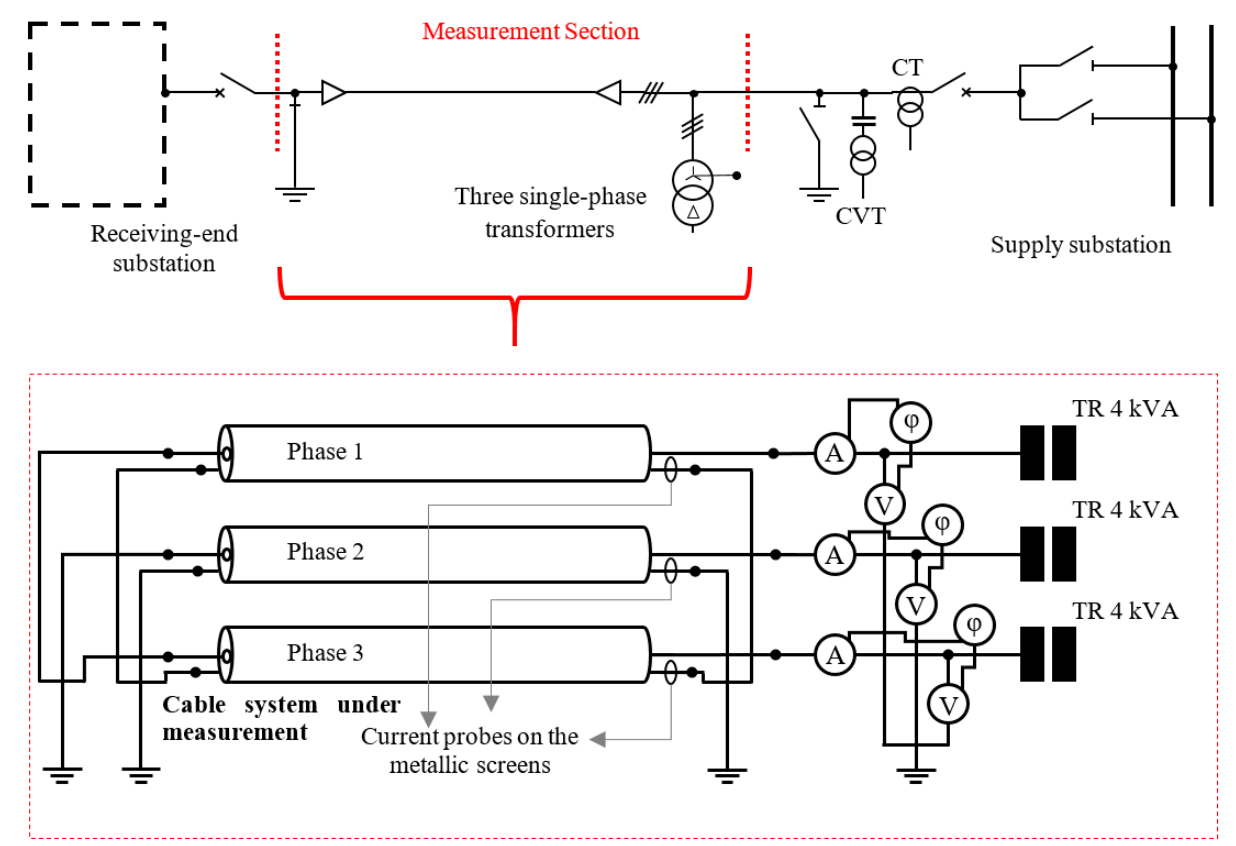

Figure 3. Equipment for measuring the positive sequence impedance. CT (not used for the sequence impedance measurements) and A stand for current transformer; CVT (not used for the sequence impedance measurements) and V stand for capacitor voltage transformer; $\varphi$ stands for phasemeter.

Figure 4 shows the scheme for measuring the zero sequence impedance. The behaviour of the current ground return path in this specific installation condition is investigated in detail in [7]. In order to supply the cable system with three equal voltages, only one transformer is used. Of course, the star 
point is earthed, and also in this case, the presence of current probes in the metallic screens allows the measurement of currents flowing in the screens.

The measured values of the p.u.l. capacitances are reported in Table 6, whereas Table 7 reports the measured positive and zero sequence impedances. Only for the case \#1, Table 8 reports the measured imposed voltage magnitudes, the current magnitudes and angles in the phases and the induced current magnitudes in the metallic screens. This will serve as a comparison with the MCA results (see Section 7).

Table 6. Measured p.u.l. capacitances of the four cases in $\mu \mathrm{F} / \mathrm{km}$.

\begin{tabular}{lcccc}
\hline & Case \#1 & Case \#2 & Case \#3 & Case \#4 \\
\hline Shunt capacitance c & 0.22 & 0.2755 & 0.2320 & 0.1889 \\
\hline
\end{tabular}

Table 7. Measured positive and zero sequence impedances in $\Omega$.

\begin{tabular}{ccc}
\hline Sequence Impedances & $\underline{\boldsymbol{Z}}_{\mathbf{1}}=\boldsymbol{R}_{\mathbf{1}}+\mathbf{j} \boldsymbol{X}_{\mathbf{1}}$ & $\underline{\boldsymbol{Z}}_{\mathbf{0}}=\boldsymbol{R}_{\mathbf{0}}+\mathbf{j} \boldsymbol{X}_{\mathbf{0}}$ \\
\hline Case \#1 & $0.3074+\mathrm{j} 1.2548$ & $1.9549+\mathrm{j} 1.0452$ \\
\hline Case \#2 & $0.1588+\mathrm{j} 0.7623$ & $0.6832+\mathrm{j} 0.3699$ \\
\hline Case \#3 & $0.2685+\mathrm{j} 1.3882$ & $2.0252+\mathrm{j} 1.0054$ \\
\hline Case \#4 & $0.0479+\mathrm{j} 0.2864$ & $0.2435+\mathrm{j} 0.1913$ \\
\hline
\end{tabular}

Table 8. Measured imposed voltage magnitudes, current magnitudes and angles in the phases and the induced current magnitudes in the metallic screens for case \#1.

\begin{tabular}{cccc}
\hline Phase Number & $\mathbf{1}$ & $\mathbf{2}$ & $\mathbf{3}$ \\
\hline Phase voltage magnitudes V & 52.27 & 52.03 & 52.05 \\
\hline Phase current magnitudes A $^{\circ}$ & 40.51 & 39.91 & 40.61 \\
\hline Phase current angles $^{\circ}$ & 76.5 & 76.1 & 76.1 \\
\hline Screen current magnitudes A $^{\circ}$ & 1.30 & 1.70 & 1.40 \\
\hline
\end{tabular}

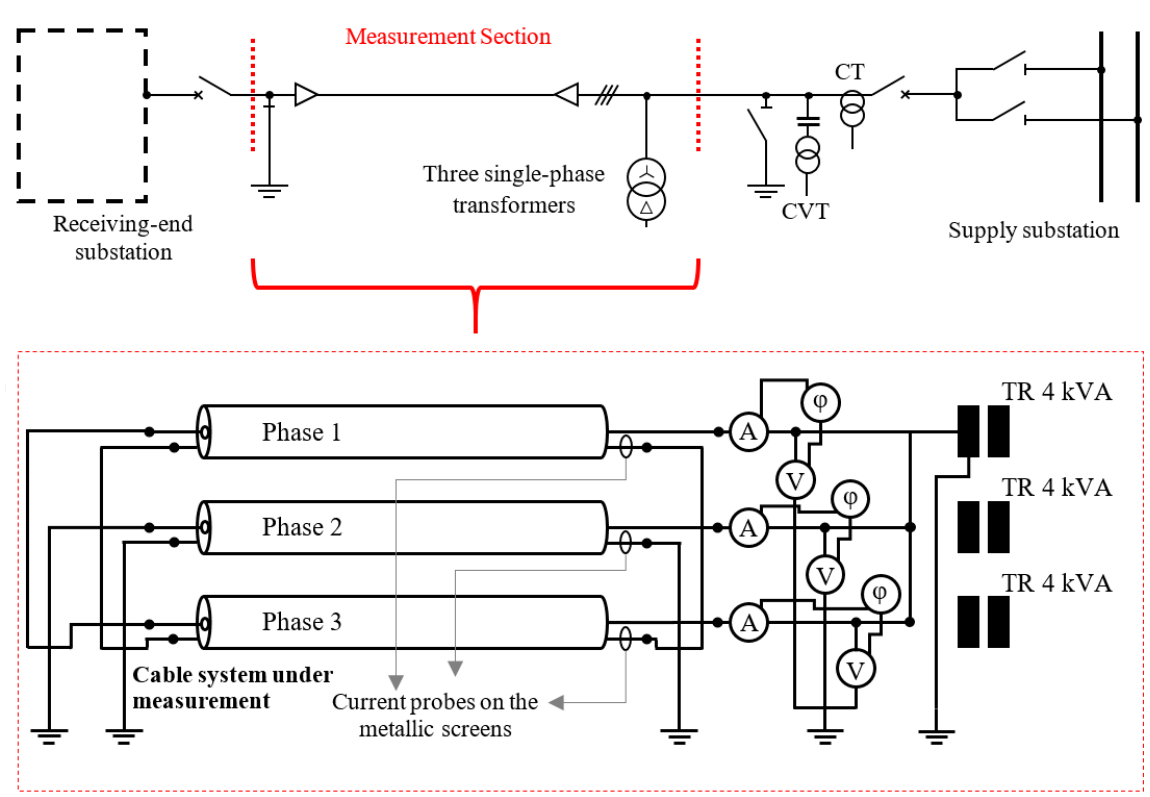

Figure 4. Equipment for measuring the zero sequence impedance. CT and A-current transformer; $\mathrm{CVT}$ and V-capacitor voltage transformer; $\varphi$ - phasemeter. 


\section{IEC/Cigré Computations}

With regard to the computation of p.u.l. phase-to-screen capacitance, the IEC formula gives:

$$
c=\frac{\varepsilon_{r}}{18 \cdot \ln \left(\frac{d_{1}}{d_{0}}\right)}\left[\frac{\mu F}{k m}\right]
$$

where $\varepsilon_{r}=$ relative permittivity of the insulating material; $d_{1}=$ outer diameter of insulating medium excluding semiconductive screen or layer; $d_{0}=$ conductor diameter including semiconductive screen or layer, if any.

The presence of semiconductive layers (around the phase conductors and the insulations) is taken into account by considering them as part of the conductors in the diameters $d_{1}$ and $d_{0}$. Table 9 reports the computed values of shunt p.u.l. capacitances for the four cases.

Table 9. Capacitances in p.u.l. of the four cases in $\mu \mathrm{F} / \mathrm{km}$ with IEC.

\begin{tabular}{lcccc}
\hline & Case \#1 & Case \#2 & Case \#3 & Case \#4 \\
\hline Shunt capacitance c & 0.2225 & 0.2802 & 0.2301 & 0.1842 \\
\hline
\end{tabular}

For each case \#1-\#4, by means of (1) and (4), the positive and zero sequence impedances are computed. The results are reported in Table 10. With regard to the case \#4, the presence of a Milliken-type conductor makes the positive sequence resistance computation difficult (i.e., the $R_{a c} / R_{d c}$ ratio) since it is not known the exact realization of Milliken conductor: therefore, the computation of skin and proximity effects are obtained with a range in the parameters $k_{s}$ and $k_{p}$ (responsible for ac resistance increase due to skin and proximity effects [26]) given by

$$
\left\{\begin{array}{c}
k_{s}=0.7-1 \\
k_{p}=0.37-1
\end{array} .\right.
$$

It is worth remembering that the IEC/Cigré formulae for cross-bonded cables implies the complete absence of induced currents in the metallic screens. This hypothesis is never verified in the real installations due to resulting asymmetry as outlined in the Introduction.

Table 10. Positive and zero sequence impedances in $\Omega$ with IEC.

\begin{tabular}{ccc}
\hline Sequence Impedances & $\underline{Z}_{\mathbf{1}}=\boldsymbol{R}_{\mathbf{1}}+j X_{\mathbf{1}}$ & $\underline{Z}_{\mathbf{0}}=\boldsymbol{R}_{\mathbf{0}}+j \boldsymbol{X}_{\mathbf{0}}$ \\
\hline Case \#1 & $0.2821+\mathrm{j} 1.2626$ & $2.0243+\mathrm{j} 0.7733$ \\
\hline Case \#2 & $0.1405+\mathrm{j} 0.7070$ & $0.7101+\mathrm{j} 0.3634$ \\
\hline Case \#3 & $0.2627+\mathrm{j} 1.2509$ & $1.9925+\mathrm{j} 0.7874$ \\
\hline Case \#4 & $(0.0311-0.035)+\mathrm{j} 0.2832$ & $(0.2235-0.2274)+\mathrm{j} 0.1523$ \\
\hline
\end{tabular}

In particular, the possibility of minor sections of different lengths is considered in another IEC standard (i.e., IEC 60287-1-1 clause 2.3.6.2 [30]) not for the computation of the sequence impedances but only for the circulating current losses with the aim of ampacity evaluation. As will be demonstrated by the measurements and by the MCA, this implies an underestimation of the positive sequence resistance and an overestimation of the positive sequence reactance.

\section{Some Notes on MCA Results}

Figure 5 shows the subdivision of the cable system into elementary cells necessary for MCA application. This Figure is also very useful to have an immediate view of the different layings (trefoil, open trefoil, flat, etc.) along the route. The very short cell length (5 $\mathrm{m}$ in both case \#1 and \#4, and in the 
other two cases, ranging from 3.62 to $10 \mathrm{~m}$ ) implies knowledge of the electric quantities with a great detail along the entire route. For the sake of brevity, it is impossible to show all the electric quantities for all the four cases.

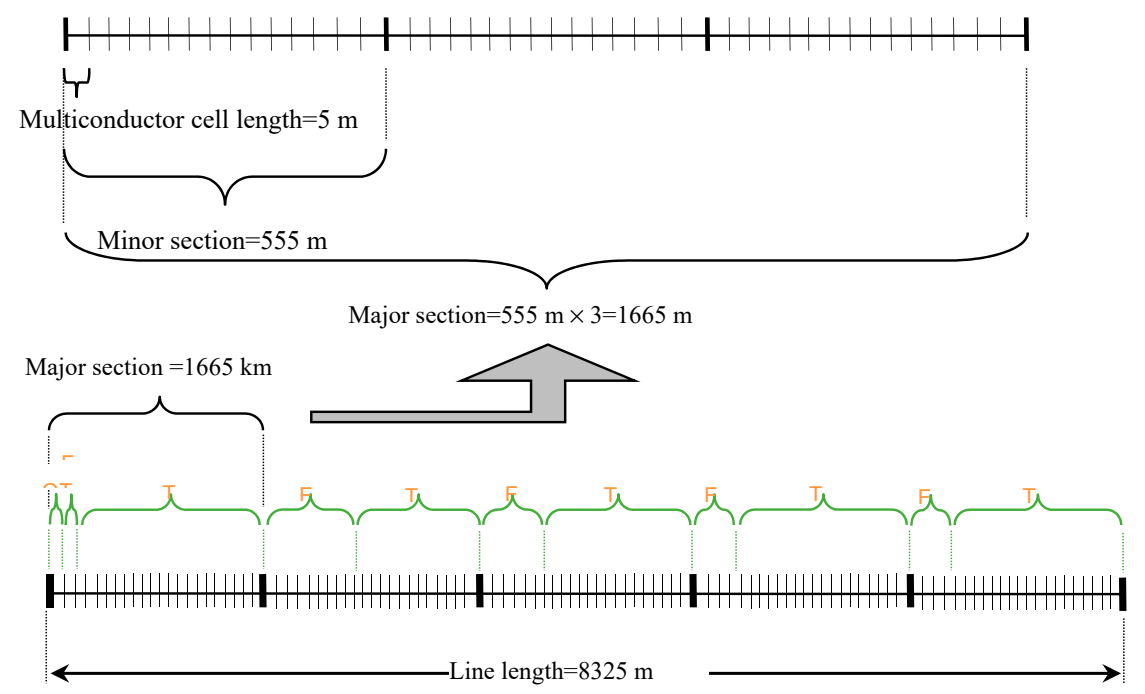

\begin{tabular}{|l|r|}
\hline OT & $50 \mathrm{~m}$ \\
\hline $\mathrm{F}$ & $55 \mathrm{~m}$ \\
\hline $\mathrm{T}$ & $1650 \mathrm{~m}$ \\
\hline $\mathrm{F}$ & $705 \mathrm{~m}$ \\
\hline $\mathrm{T}$ & $900 \mathrm{~m}$ \\
\hline $\mathrm{F}$ & $475 \mathrm{~m}$ \\
\hline $\mathrm{T}$ & $1180 \mathrm{~m}$ \\
\hline $\mathrm{F}$ & $275 \mathrm{~m}$ \\
\hline $\mathrm{T}$ & $1380 \mathrm{~m}$ \\
\hline $\mathrm{F}$ & $275 \mathrm{~m}$ \\
\hline $\mathrm{T}$ & $1380 \mathrm{~m}$ \\
\hline
\end{tabular}

Figure 5. Subdivision of case \#1 in elementary cells, minor and major sections. OT—open trefoil with spacing $=0.15 \mathrm{~m} ; \mathrm{F}$-flat laying with spacing $=1 \mathrm{~m} ; \mathrm{T}$-close trefoil.

Since the errors in the evaluation of positive sequence impedances by means of IEC/Cigré depend upon the existence of induced screen currents even if the screens are cross-bonded, Figure 6 shows the inducing currents in the phases, and Figure 7 the induced currents in the metallic screens. The current magnitudes in Figure 6 are obtained by imposing the same voltage generators of the corresponding measurement campaign (see Table 8 first row) such as to compare the phase and the induced screen currents. It is impressive how the measured current magnitudes induced in the screens (see Table 8 last row) at the sending end present a slight difference compared to the values at the beginning (i.e., $x$ $=0 \mathrm{~km}$ ) of the $x$-axes of Figure 7 . The screen current magnitudes vary along the route of the cable due to the different lengths in the cross-bonding minor sections which determine the non-zero induced currents in the screens, which reach almost $9 \mathrm{~A}$ (or about $40 \mathrm{~A}$ in the phases). This demonstrates the influence of circulating currents in the screens on the positive sequence parameters.

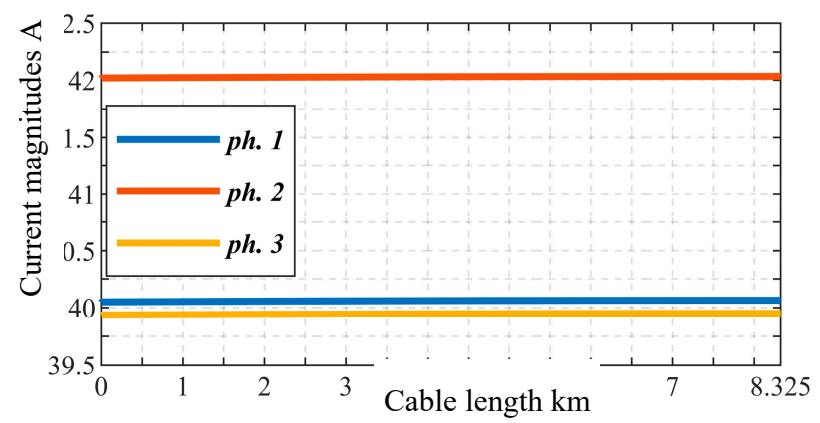

Figure 6. Current magnitudes in the three phases for case \#1 (current magnitudes). 


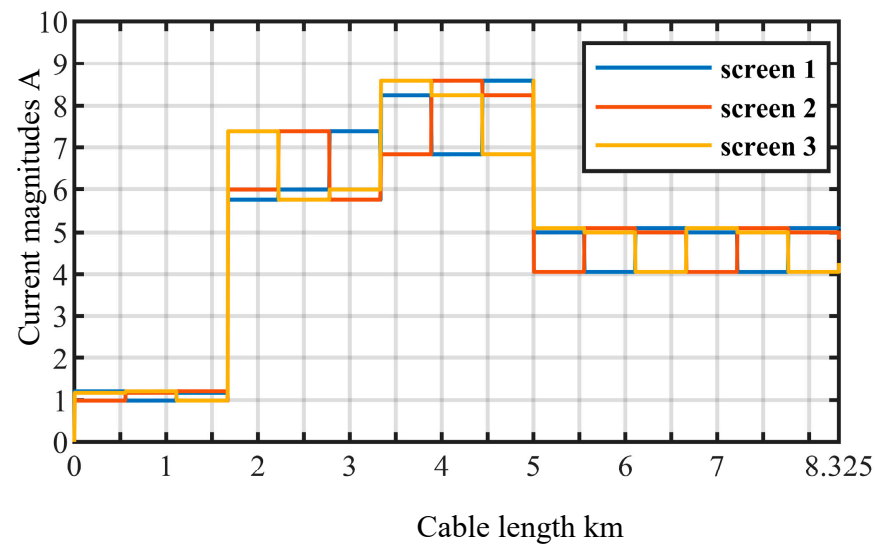

Figure 7. Induced current magnitudes in the three screens for case \#1.

Figures 8-10 give the subdivision into elementary cells performed for cases \#2-\#4.

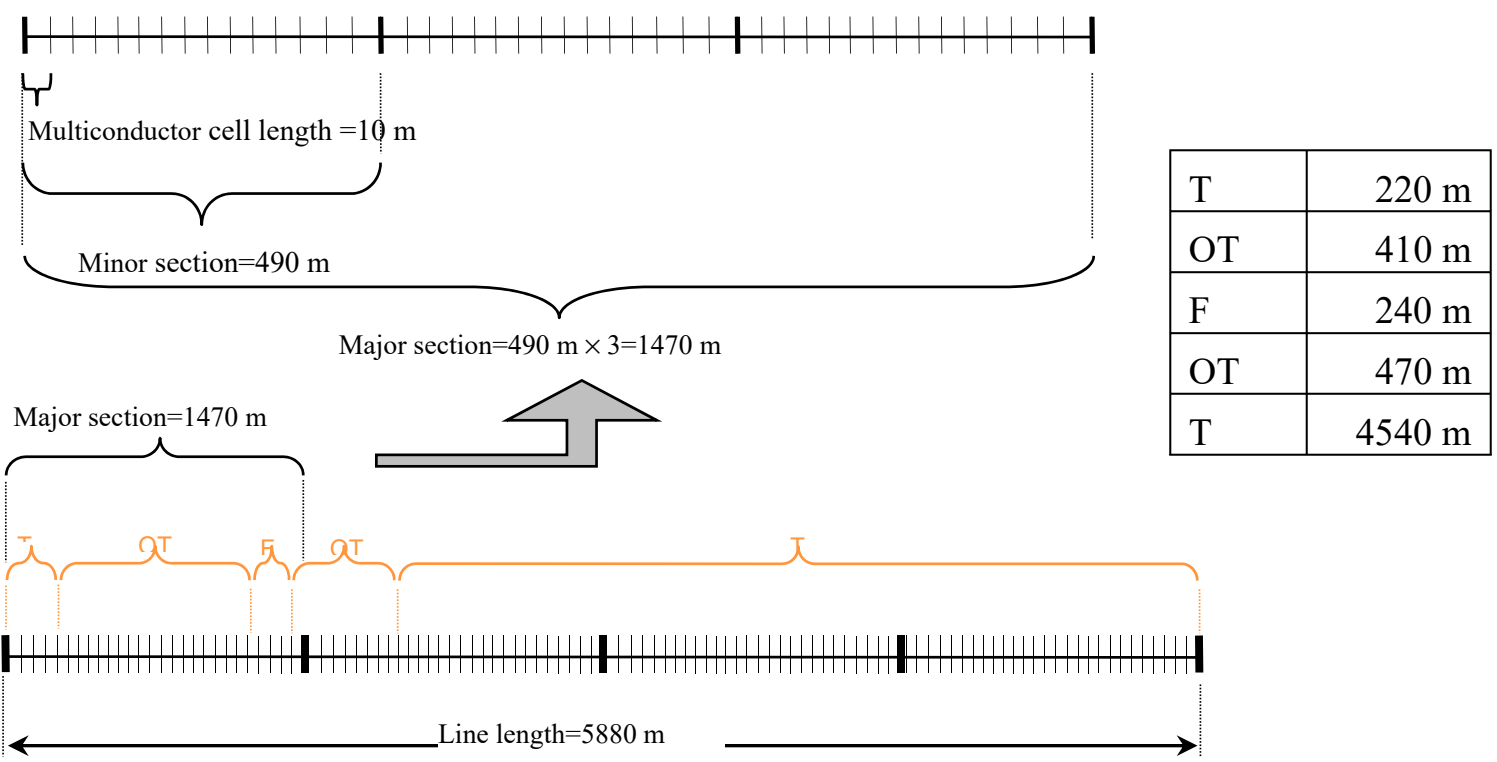

Figure 8. Subdivision of case \#2 in elementary cells, minor and major sections. OT-open trefoil with spacing $=0.225 \mathrm{~m} ; \mathrm{F}$-flat laying with spacing $=0.35 \mathrm{~m}$; $\mathrm{T}$-close trefoil.

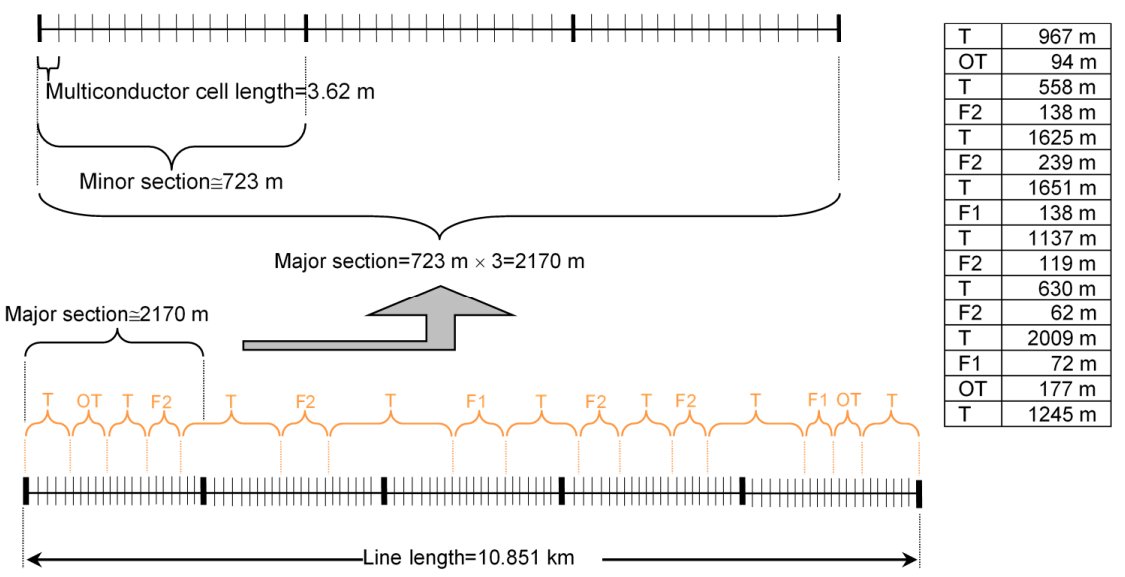

Figure 9. Subdivision of case \#3 in elementary cells, minor and major sections. OT-open trefoil with spacing $=0.18 \mathrm{~m} ; \mathrm{F} 1$-flat laying with spacing $=0.25 \mathrm{~m} ; \mathrm{F} 2$-flat laying with spacing $=0.5 \mathrm{~m}$; $\mathrm{T}$-close trefoil. 
Table 11 reports the computations of p.u.l. shunt capacitance taking into account the semiconductive layers, but the results are practically identical to those obtained with IEC formula in (9).

It is worth noting that also commercial software as EMTP-RV or DigSilent Power Factory can reach the same precision of $\mathrm{MCA}$.

The advantage of MCA is that it is a free self-made matrix algorithm whose inner characteristics are not hidden but available in the technical literature.
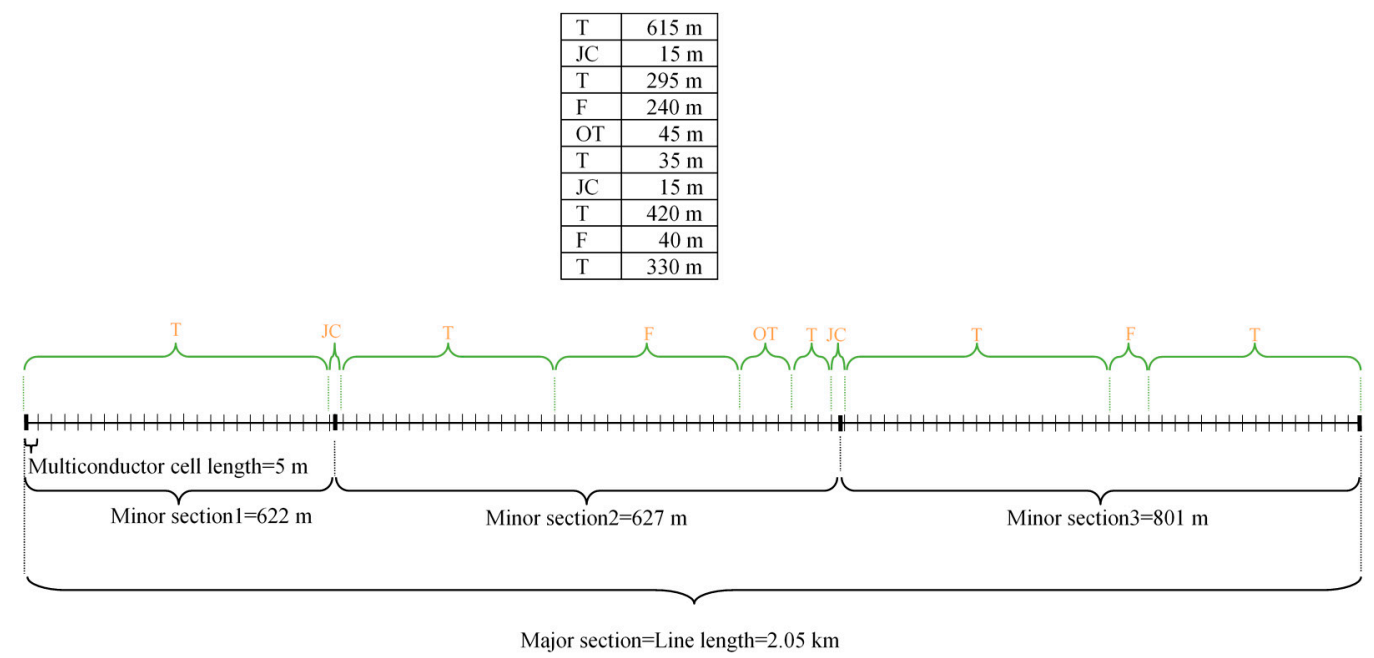

Figure 10. Subdivision of case \#4 in elementary cells, minor and major sections. OT-open trefoil with spacing $=0.2 \mathrm{~m} ; \mathrm{F}$-flat laying with spacing $=0.6 \mathrm{~m} ; \mathrm{T}$-close trefoil; JC—joint chamber.

Table 11. The p.u.l. capacitances of the four cases in $\mu \mathrm{F} / \mathrm{km}$ with multiconductor cell analysis (MCA).

\begin{tabular}{ccccc}
\hline & Case \#1 & Case \#2 & Case \#3 & Case \#4 \\
\hline $\begin{array}{c}\text { Shunt p.u.l. } \\
\text { capacitance c }\end{array}$ & 0.2225 & 0.2802 & 0.2301 & 0.1842 \\
\hline
\end{tabular}

For each case \#1-\#4, by means of (6) and (8), the positive and zero sequence are computed. The results are reported in Table 12.

Table 12. The p.u.l. posit. and zero sequence impedances in $\Omega$ with MCA.

\begin{tabular}{ccc}
\hline Sequence Impedances & $\underline{Z}_{1}=\boldsymbol{R}_{\mathbf{1}}+j \boldsymbol{X}_{\mathbf{1}}$ & $\underline{Z}_{\mathbf{0}}=\boldsymbol{R}_{\mathbf{0}}+\mathbf{j} \boldsymbol{X}_{\mathbf{0}}$ \\
\hline Case \#1 & $0.3064+\mathrm{j} 1.2446$ & $2.1911+\mathrm{j} 0.819$ \\
\hline Case \#2 & $0.1558+\mathrm{j} 0.7027$ & $0.7256+\mathrm{j} 0.3587$ \\
\hline Case \#3 & $0.2767+\mathrm{j} 1.3694$ & $1.9991+\mathrm{j} 0.7672$ \\
\hline Case \#4 & $(0.0432-0.0451)+\mathrm{j} 0.277$ & $(0.2807-0.2827)+\mathrm{j} 0.1518$ \\
\hline
\end{tabular}

It is worth noting that the results of commercial power systems software as EMTP-RV would give the same results of MCA. For power frequency analysis, the authors prefer to use MCA since it is an open-source algorithm and allows knowing all the hypotheses and assumptions which are the basis of computations. By contrast, the commercial software are black boxes.

\section{Final Comparisons of MCA and IEC/Cigrè with Measurements}

In order to have a general overview of the differences between the two computation methods and the measurements, Table 13 reports the percentage errors of MCA and of IEC/Cigré with respect to 
the measurement values. For example, the error of $M C A$ with respect to the measurements (acronym $M E A)$ are expressed by

$$
\begin{gathered}
\Delta e_{\mathcal{C}}=\frac{c_{M E A}-c_{M C A}}{c_{M E A}} \cdot 100 ; \\
\Delta e_{R 1}=\frac{R_{1 \_M E A}-R_{1 \_M C A}}{R_{1 \_M E A}} \cdot 100 ; \Delta e_{X 1}=\frac{X_{1 \_M E A}-X_{1 \_} M C A}{X_{1 \_} M E A} \cdot 100 ; \\
\Delta e_{R 0}=\frac{R_{0 \_M E A}-R_{0 \_} M C A}{R_{0 \_M E A}} \cdot 100 ; \Delta e_{X 0}=\frac{X_{0 \_M E A}-X_{0 \_} M C A}{X_{0 \_M E A}} \cdot 100 .
\end{gathered}
$$

The cell colours help to immediately visualise the error ranges with the following choices:

- $\quad$ RED for errors greater than $15 \%$;

- YELLOW for errors ranging between $7.5 \%$ and $15 \%$;

- GREEN for errors smaller than $7.5 \%$.

The first important outcome of this research is that the precision in the computation of shunt capacitance of land single-core cables is very high both with IEC formula and with MCA which also considers semiconductive layers: the measures confirm that, at power frequency, the effects of

\begin{tabular}{|c|c|c|c|c|c|c|c|c|c|c|c|c|c|}
\hline \multicolumn{14}{|c|}{ COMPARISON BETWEEN THE DIFFERENT METHODS APPLIED TO THE ANALYSED CASE STUDIES } \\
\hline & & \multicolumn{3}{|c|}{$\begin{array}{c}\text { Case \#1 } \\
\text { SE Calenzano-SE } \\
\text { Rifredi RT }\end{array}$} & \multicolumn{3}{|c|}{$\begin{array}{c}\text { Case \#2 } \\
\text { CP S. Giuseppe-CP } \\
\text { Portoferraio }\end{array}$} & \multicolumn{3}{|c|}{$\begin{array}{c}\text { Case \#3 } \\
\text { SE Camin-CP } \\
\text { Bassanello }\end{array}$} & \multicolumn{3}{|c|}{$\begin{array}{c}\text { Case \#4 } \\
\text { CP Ferrara Nord-C.le SEF }\end{array}$} \\
\hline & & $\begin{array}{l}\text { IEC } \\
\text { Cigré }\end{array}$ & MCA & Mea. & $\begin{array}{l}\text { IEC } \\
\text { Cigré }\end{array}$ & MCA & Mea. & $\begin{array}{l}\text { IEC } \\
\text { Cigré }\end{array}$ & MCA & Mea. & $\begin{array}{l}\text { IEC } \\
\text { Cigré }\end{array}$ & MCA & Mea. \\
\hline$c$ & $\mu \mathrm{F} / \mathrm{km}$ & 0.2224 & 0.2224 & 0.2200 & 0.2802 & 0.2802 & 0.2755 & 0.2301 & 0.2301 & 0.2320 & 0.1842 & 0.1842 & 0.1889 \\
\hline$\Delta \mathrm{e}$ & $\%$ & 8.23 & 0.33 & 0.3074 & 11.52 & 1.89 & \multirow{3}{*}{0.7623} & 8.31 & 3.42 & 0.2865 & $35 \div 26.9$ & $9.3 \div 5.9$ & 0.0479 \\
\hline$X_{1}$ & $\Omega$ & 1.2626 & 1.2446 & \multirow[t]{2}{*}{1.2548} & 0.7069 & 0.7063 & & 1.2509 & 1.3694 & \multirow[t]{2}{*}{1.3882} & 0.2832 & 0.2769 & \multirow[t]{2}{*}{0.2864} \\
\hline$\Delta e$ & $\%$ & -0.62 & 0.81 & & 7.27 & 7.35 & & 9.89 & 1.35 & & 1.12 & 3.32 & \\
\hline$R_{0}$ & $\Omega$ & 2.0243 & 2.0239 & 1.9549 & 0.7101 & 0.7256 & 0.6832 & 1.9925 & 1.9991 & \multirow[t]{2}{*}{2.0252} & $0.2235 \div 0.2274$ & $0.2406 \div 0.2434$ & \multirow[t]{2}{*}{0.2435} \\
\hline$\Delta e$ & $\%$ & -3.55 & -3.53 & 1.0452 & -3.94 & -6.21 & 0.3699 & 1.61 & 1.29 & & $8.2 \div 6.6$ & $-1.19 \div-0.04$ & \\
\hline
\end{tabular}
semiconductive layers can surely be neglected.

Table 13. Final comparisons of the measurements with MCA and IEC/Cigré computations.

The second result is the strong underestimation (up to 35\%) of IEC/Cigré positive sequence resistances due to the already highlighted wrong hypothesis of null screen circulating currents.

The third note deals with the great errors in the zero sequence reactance (always about $20 \%$ both for MCA and IEC/Cigré) in all the cases (\#1,\#3, and \#4) of cable located in industrialised and urbanised areas. This is due to the fact that the repartition of the currents between screens and earth is influenced by the presence of underground metallic pipes which are not known.

The demonstration of this fact is that for case \#2, located in a natural area, the errors are wholly negligible (about 3\%). In any case, since the calculated value is lower than that measured, this is on the safe side for the calculation of the short circuit currents but may lead to an error in the setting of the distance relays and consequent untimely tripping.

\section{Conclusions}

The formula IEC/Cigré for the computation of the phase-to-screen capacitance (equal for both positive and zero sequences) gives extremely precise values in full agreement with measurements when the relative permittivity and the semiconductive screen thicknesses are known. The maximum error is smaller than $2.5 \%$. The same error is given by MCA even if it considers the relative permittivities of semiconductive layers. All the direct formulae of the positive sequence impedance hypothesise that 
the screen arrangements completely zero the induced currents in the screens. This would be true in real installations only if:

(1) The minor section lengths are exactly equal (practically impossible);

(2) There is perfect laying symmetry along the route (trefoil laying or any laying performed with phase transpositions: both very difficult to obtain).

In engineering practice (very often, the "as-built" differs from the project specifications) one or both the conditions cannot be satisfied. This gives errors between $8 \%$ and $35 \%$ for the real part of positive sequence impedance and up to $8 \%$ in the imaginary part.

In these cases, the hypotheses for Carson theory applications fail so that the ground return current uses different metallic paths and, therefore, nor analytical formulae neither matrix procedures can give exact impedance values.

MCA, together with commercial software as DigSilent PowerFactory or EMTP-RV, is the only computation approach able to obtain zero and positive sequence impedances in tune with the measurements when the exact laying conditions, homogeneous stretch per homogeneous stretch, are known. This is demonstrated by the fact that an error greater than $20 \%$ is given only in presence of unknown metallic return path for the currents.

Hence, the paper demonstrates, for the first time in the technical literature, that direct formulae cannot correctly evaluate the sequence impedances of installed single-core land cable systems. Extensive on-field measurement campaigns have served to this purpose.

Only by considering all the conductors (active and passive ones) in their real arrangement, it is possible to have reliable and correct sequence impedance values. The authors have extensively used their open-source algorithm, i.e., MCA, in order to demonstrate that the differences with on-field measurements are always negligible. The only difference between measurements and MCA results persists in the zero sequence reactance but only when cable systems are installed in urban or industrialised areas. This is not due to MCA limitations but only to the presence of different underground subservices (e.g., gas metallic pipes, etc.) in urbanised or industrialised areas, which alter the current return path. The final scientific demonstration of this important conclusion comes from the measurements of zero sequence in the cable system installed in Elba Island Island (CP S. Giuseppe-CP Portoferraio, i.e., case \#3) where there is no congestion of underground subservices which lead to errors in determination the current return path. Hence, MCA can correctly evaluate also the zero sequence reactance with a difference of about $3 \%$ compared to measurements.

In conclusion, in this paper, we aim to help the entire insulated cable community to become aware of and pay attention to the issues in computation of sequence impedances with simplified analytic direct formulae: they can give high errors, which jeopardise the evaluations and the settings involving sequence impedance values.

Author Contributions: Conceptualization, R.B., S.D.S., M.P.; Investigation R.B., S.D.S., F.S.; Formal Analysis, R.B., S.D.S., F.S.; Writing Original Draft Preparation, Review \& Editing R.B., S.D.S.; Supervision, R.B.; Project Administration, R.B., M.P.; Funding Acquisition, M.P. All authors have read and agreed to the published version of the manuscript.

Funding: This research was funded by [Ensiel/Terna], grant number [ST16].

Conflicts of Interest: The authors declare no conflict of interest.

\section{References}

1. Benato, R.; Caciolli, L. Sequence impedances of insulated cables: Measurements versus computations. PES TED 2012, 2012, 1-7. [CrossRef]

2. IEC 60909-2: Short-Circuit Currents in Three-Phase a.c. Systems-Part 2: Data of Electrical Equipment for Short-Circuit Current Calculations, 2nd ed.; IEC: Geneva, Switzerland, 2008. 
3. Royer, C.; Dorison, E.; Anderson, N.; Benato, R.; Brijs, B.; Chang, K.W.; Falconer, A.; Fernandez, S.; Gudmunsdottir, U.S.; Li, J.; et al. Cable Systems Electrical Characteristics. Technical Report for CIGRE Technical Brochure $\mathrm{N}^{\circ}$ 531. 2013. Available online: https://e-cigre.org/publication/531-cable-systemselectrical-characteristics (accessed on 28 February 2020).

4. Ametani, A.; Ohno, T. Derivation of Theoretical Formulas of Sequence Currents on Underground Cable Systems. IEEJ Trans. Power Energy 2011, 131, 277-282. [CrossRef]

5. Ramya, G.M.; Radhika, P. Computation of Sequence Impedances for 220kv Underground Cable with Different Short Circuit Capacities. Int. J. Mod. Trends Sci. Technol. 2017, 3. Available online: http://www.ijmtst.com (accessed on 28 February 2020).

6. Benato, R. Multiconductor analysis of underground power transmission systems: EHV AC cables. Electr. Power Syst. Res. 2009, 79, 27-38. [CrossRef]

7. Benato, R.; Paolucci, A. Multiconductor cell analysis of skin effect in Milliken type cables. Electr. Power Syst. Res. 2012, 90, 99-106. [CrossRef]

8. Benato, R.; Napolitano, D. Overall Cost Comparison between Cable and Overhead Lines Including the Costs for Repair After Random Failures. IEEE Trans. Power Deliv. 2012, 27, 1213-1222. [CrossRef]

9. Benato, S.R.; Dambone Sessa, F.; Guglielmi, E.; Partal, E.; Tleis, N. Ground Return Current Behaviour in High Voltage Alternating Current Insulated Cables. Energies 2014, 7, 8116-8131. [CrossRef]

10. Benato, R.; Sessa, S.D.; De Zan, R.; Guarniere, M.; Lavecchia, G.; Labini, P.S. Different Bonding Types of Scilla-Villafranca (Sicily-Calabria) 43 km Double-Circuit AC 380 kV Submarine-Land Cable. IEEE Trans. Ind. Appl. 2015, 51, 5050-5057. [CrossRef]

11. Benato, R.; Colla, L.; Sessa, S.D.; Marelli, M. Review of high current rating insulated cable solutions. Electr. Power Syst. Res. 2016, 133, 36-41. [CrossRef]

12. Benato, R.; Sessa, S.D.; Guglielmi, F.; Partal, E.; Tleis, N. Zero sequence behaviour of a double-circuit overhead line. Electr. Power Syst. Res. 2014, 116, 419-426. [CrossRef]

13. Benato, R.; Sessa, S.D.; Guizzo, L.; Rebolini, M. The synergy of the future: high voltage insulated power cables and railway-highway infrastructures. IET Gener. Transm. Distrib. 2017, 11, 2712-2720. [CrossRef]

14. Benato, R.; Sessa, S.D. A New Multiconductor Cell Three-Dimension Matrix-Based Analysis Applied to a Three-Core Armoured Cable. IEEE Trans. Power Deliv. 2018, 33, 1636-1646. [CrossRef]

15. Carson, J.R. Wave Propagation in Overhead Wires with Ground Return. Bell Syst. Tech. J. 1926, 5, 539-554. [CrossRef]

16. Pollaczek, F. Über das Feld einer unendlich langen wechsel stromdurchflossenen Einfachleitung. Electrishe Nachrichten Technik 1926, 3, 339-360.

17. CCITT. Directives Concerning the Protection of Telecommunication Lines against Harmful Effects from Electric Power and Electrified Railway Lines; CCITT: Geneva, Switzerland, 1989.

18. Schelkunhoff, S.A. The electromagnetic theory of coaxial transmission lines and cylindrical shields. Bell Syst. Tech. J. 1934, 13, 532-579. [CrossRef]

19. Wedepohl, L.M.; Wilcox, D.J. Transient analysis of underground power transmission systems. Proc. IEEE 1973, 120, 253-260.

20. Benato, R.; Sessa, S.D.; Forzan, M. Experimental Validation of 3-Dimension Multiconductor Cell Analysis by a $30 \mathrm{~km}$ Long Submarine Three-Core Armoured Cable. IEEE Trans. Power Deliv. 2018, 33, 2910-2919. [CrossRef]

21. Choi, J.K.; Kwak, J.S.; Lee, W.K.; Jung, C.K.; Kim, J.W.; Oh, S.I. Analysis of Sequence impedance of 345 kV Cable systems with Special bondings using ATP. In Proceedings of the 2009 Transmission \& Distribution Conference \& Exposition: Asia and Pacific, Seoul, South Korea, 26-30 October 2009.

22. Gudmundsdottir, U.S.; Gustavsen, B.; Bak, C.L.; Wiechowski, W. Field Test and Simulation of a 400-kV Cross-Bonded Cable System. IEEE Trans. Power Deliv. 2011, 26, 1403-1410. [CrossRef]

23. Das, J.C. Understanding Symmetrical Components for Power System Modelling; IEEE Press Wiley: Hoboken, NJ, USA, 2017.

24. Tleis, N. Power Systems Modelling and Fault Analysis: Theory and Practice, 2nd ed.; Newnes: London, UK, 2019.

25. Blackburn, J.L. Symmetrical Components for Power Systems Engineering; CRC Press: Boca Raton, FL, USA, 1993.

26. IEC 60909-3: Short-Circuit Currents in Three-Phase a.c. Systems-Part 3: Currents during Two Separate Simultaneous Line-to-Earth Short-Circuits and Partial Short-Circuit Currents Flowing through Earth; IEC: Geneva, Switzerland, 2010. 
27. IEC EN 60044-1, Instrument Transformers_Part 1: Current Transformers; IEC: Geneva, Switzerland, 1999.

28. IEC EN 60044-5, Instrument Transformers-Part 5: Capacitor Voltage Transformers; IEC: Geneva, Switzerland, 2004.

29. Callegaro, L. Electrical Impedance Principles, Measurement, and Applications; Taylor \& Francis Group: Milton Park, UK, 2013.

30. IEC 60287: Electric Cables—Calculation of the Current Rating, (in 8 parts: 1.1, 1.2, 1.3, 2.1, 2.2, 3.1, 3.2, 3.3); IEC: Geneva, Switzerland, 2015. 